\title{
Highlights in Plasma Physics
}

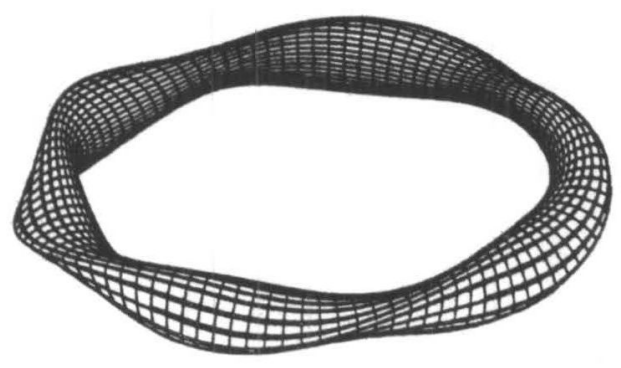

Three-dimensional picture of a flux surface of an $I=$ 2 stellarator. The elliptical cross section rotates poloidally when traversing toroidally.

W.D.D'haeseleer, W.N. G. Hitchon, J.D. Callen, J. L. Shohet

\section{Flux Coordinates and Magnetic Field Structure}

\section{A Guide to a Fundamental Tool of Plasma Theory}

1991. XII, 241 pp. 40 figs. (Springer Series in Computational Physics) Hardcover DM 158,ISBN 3-540-52419-3

Flux Coordinates and Magnetic Field Structure gives a systematic and rigorous presentation of the mathematical framework and principles underlying the description of magnetically confined fusion plasmas. After a brief treatment of vector algebra in curvilinear coordinate systems the book introduces concepts such as flux surfaces, rotational transforms, and magnetic differential equations. The various specific types of coordinate system are dealt with in detail.

Researchers and advanced students in plasma physics, electromagnetics, and mathematical physics will greatly benefit from this useful guide and reference book.
A. L. Peratt

\section{Physics of the Plasma Universe}

1991. Approx. 250 pp. 208 figs. Hardcover DM 148,- ISBN 3-540-97575-6

During the past decade our understanding of plasma physics has witnessed an explosive growth due to research in two areas: work directed toward controlled nuclear fusion and work in space physics. This book addresses the growing need to apply these complementary discoveries to astrophysics. Today plasma is recognized as the key element to understanding the generation of magnetic fields in planets, stars and galaxies, the acceleration and transport of cosmic rays, and many other phenomena occurring in interstellar space, in radio galaxies, stellar atmospheres, quasars, and so forth.

Contents: Cosmic Plasma Fundamentals. Birkeland Currents in Cosmic Plasma. Biot-Savart Law in Cosmic Plasma. Electric Fields in Cosmic Plasma. - Double Layers in Astrophysics. - Synchrotron Radiation. - Transport of Cosmic Radiation. - Particle-in-Cell Simulation of Cosmic Plasma. - Appendix A. Transmission Line Fundamentals in Space and Cosmic Plasmas. - Appendix B. Polarization of Electromagnetic Waves in Plasma. - Appendix C. Dusty and Grain Plasmas. -

Appendix D.

Some Useful

Relations. -

References. -

Author Index. -

Subject Index.

$\square$ Heidelberger Platz 3, W-1000 Berlin 33, F. R. Germany $\square$ 175 Fifth Ave., New York. NY 10010. USA

$\square 8$ Alexandra Rd. London SWI9 7JZ, England $\square$ 26, rue des Carmes, F-75005 Paris, France

[7 37, Hongo 3-chome, Bunkyo-ku. Tokyo I13, Japan

Room 701. Mirror Tower, 6I Mody Road. Tsimshatsui, Kowloon, Hong Kong

$\square$ Avinguda Diagonal, $468-4^{\circ} \mathrm{C}$. E-08006 Barcelona, Spain $\square$ Wessclényi u. 28, H-1075 Budapest, Hungary

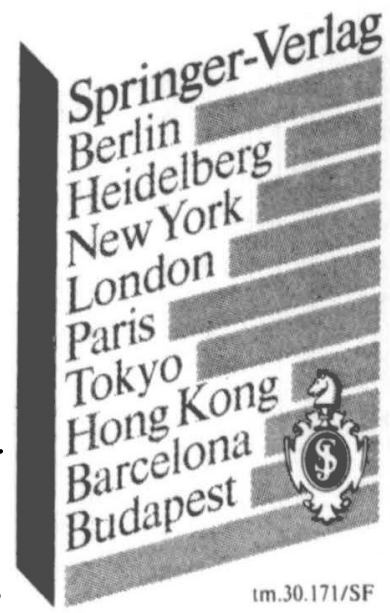




\section{JOURNAL OF PLASMA PHYSICS}


Journal of Plasma Physics exists for the publication of experimental and theoretical research papers on plasma physics and its applications.

\author{
EDITOR \\ DR J. P. DOUGHERTY \\ Department of Applied Mathematics and Theoretical Physics, University of Cambridge, \\ Silver Street, Cambridge CB3 $9 E \mathrm{~W}$, England \\ ASSOCIATE EDITORS \\ Prof. D. BERSHADER \\ Department of Aeronautics and Astronautics, \\ Stanford University, Stanford, California 94305, USA \\ DR E. INFELD \\ Institute of Nuclear Research, Hoza 69, PL-00-681, Warsaw, Poland \\ PROF. P. K. KAW \\ Institute for Plasma Research, Bhat, Gandhinagar 382 424, India
}

Authors wishing to have papers published in the Jo URN A L should communicate them to any one of the persons named above, choosing one in their own country where possible.

Authors are urged to ensure that their papers are written clearly and attractively, in order that their work will be readily accessible to readers.

Manuscripts should be typed in double spacing on one side of the paper only, with references listed at the end in alphabetical order of authors. Drawings should be done in Indian ink on plain white or transparent paper, and should not be larger than $15 \mathrm{in}$. by 24 in. Lettering should be shown clearly in pencil for reproduction by the printer, and as far as possible information relating to a figure should be placed in the caption rather than on the figure. A typed list of captions should be provided at the end of the manuscript. Proofs of papers from overseas will usually be despatched to authors by airmail. There is no charge for publication. Authors are entitled to receive 50 offprints of a paper in the JoURNA L free of charge, and additional offprints can be purchased if ordered in advance.

\title{
Copying
}

(C) Cambridge University Press 1991

This journal is registered with the Copyright Clearance Center, 27 Congress St., Salem, Mass. 01970. Organizations in the USA who are also registered with C.C.C. may therefore copy material (beyond the limits permitted by sections 107 and 108 of US copyright law) subject to payment to C.C.C. of the per copy fee of $\$ 05.00$. This consent does not extend to multiple copying for promotional or commercial purposes. Code 0022-3778/91 $\$ 5.00+.00$.

ISI Tear Sheet Service, 3501 Market Street, Philadelphia, Pennsylvania 19104, USA, is authorized to supply single copies of separate articles for private use only.

For all other use, permission should be sought from Cambridge or the American Branch of Cambridge University Press.

Journal of Plasma Physics (ISSN 0022-3778) is published once every two months in February, April, June, August, October and December, by Cambridge University Press, The Edinburgh Building, Shaftesbury Road, Cambridge CB2 2RU and Journals Department, 40 West 20th Street, New York, NY 10011-4211.

Three parts form a volume. The subscription price (which includes postage) of Volumes 45 and $46(1991)$ is $\$ 115.00$ net UK, $£ 117.00$ elsewhere per volume (US $\$ 239.00$ in the USA and Canada) for institutions; $\mathfrak{1 5 7 . 5 0}$ (US $\$ 175.00$ ) per volume for individuals. Single parts cost $£ 39.00$ each (US $\$ 79.00$ in the USA and Canada) plus postage. All orders must be accompanied by payment.

Copies of the journal for subscribers in the United States of America and Canada are sent by air to New York to arrive with minimum delay.

Second class postage paid at New York, NY, and at additional mailing offices. POSTMASTER: send address changes in USA, and Canada to Journal of Plasma Physics, Cambridge University Press, 110 Midland Avenue, Port Chester, New York, NY 10573-9864. 


\section{JOURNAL OF PLASMA PHYSICS}

VOLUME 46

1991

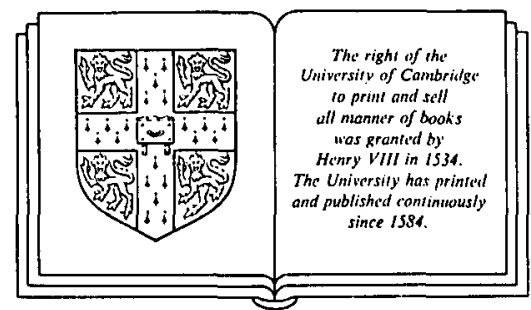

CAMBRIDGE UNIVERSITY PRESS Cambridge

New York Port Chester Melbourne Sydnoy 
Published by the Press Syndicate of the University of Cambridge

The Pitt Building, Trumpington Street, Cambridge CB2 1RP

40 West 20th Street, New York, NY 10011-4211

10 Stamford Road, Oakleigh, Victoria 3166, Australia

(C) Cambridge University Press 1991

Printed in Great Britain by the University Press, Cambridge 


\section{CONTENTS TO VOLUME 46}

\section{Part 1 August 1991}

Electron-acoustic instability driven by a field-aligned hot electron beam. R. BHARUTHRAM

Weyl's theorem for magnetohydrodynamics. G. P. ZANk

Nonlinear surface Alfvén waves. N. F. Cramer

Magnetic field intensification and formation of field-aligned current in a non-uniform magnetic field. H. MURATa

Drift instability in the presence of a parallel electric field and an inhomogeneous magnetic field: particle aspect analysis. M. S. TIWARI and P. VARMA

Numerical simulations of BGK modes. L. Demeio and J. P. Holloway

Instability of intensely propagating circularly polarized electrornagnetic pulses in a two-component plasma. R. E. KATES and D. J. K.AUP

Scattering of electromagnetic waves by hybrid waves in a two-electrontemperature plasma. S. K. Sharma and S. SudarshaN

Parametric instabilities of circularly polarized large-amplitude dispersive Alfvén waves: excitation of parallel-propagating electromagnetic daughter waves. A. F. VIÑNAS and M. L. GoldSTEIN

Parametric instabilities of circularly polarized large-amplitude dispersive Alfvén waves: excitation of obliquely-propagating daughter and sideband waves. A. F. VIÑAs and M. L. GoldSTEIN

Bistability of a forced hydromagnetic cavity. L. Nocera and E. R. PRIEST

A physical description of magnetic helicity evolution in the presence of reconnection lines. A. N. WRIGHT and M. A. Berger

\section{Part 2 OCtober 1991}

Scattering of circularly polarized electromagnetic waves off a straight electron beam propagating along a constant magnetic field. A. BOGDANOV

Theory of nonlinear interaction of particles and waves in an inverse plasma maser. Part 1. Collision integral. V. S. KrIvitsky and S. V. VLADIMIROV 
Theory of nonlinear interaction of particles and waves in an inverse plasma maser. Part 2. Stationary solution and evolution of initial distributions. V. S. KRIVITSKY and S. V. VLADIMIROV

On the decay of a dipole pump wave to half-harmonics. J. A. HeIkKInen, T. J. H. P̈̈tTIKangas and G. Devillers

Observations of low-frequency oscillations during relativistic-electronbeam-plasma interactions. A. S. Paithankar and G. P. Gupta

On the existence of ion-acoustic double layers in negative-ion plasmas. S. Baboolal, R. Bharuthram and M. A. Hellberg

A generalization of the Taylor constraint to the advection of axisymmetric poloidal magnetic fields. P. A. WATTERSON

Analytical solutions for the current driven by a rotating magnetic field in a spherical plasma. P. A. WatTERSON

Parametric excitation of surface waves in a strongly inhomogeneous plasma. G. Brodin and J. LUNDBERG

The effect of cosmic rays on the instability of a tangential discontinuity.

S. V. Chalov

Modulational instability produced by Alfvénic turbulence in a collisionless plasma. H. Hamabata

Plasma maser theory of the extraordinary mode in the presence of Langmuir turbulence. S. N. Sarma, K. K. Sarma and M. NambU

Space-dependent quasi-linear theory of lower-hybrid waves. E. Canobiro and R. Croci

\section{PART 3 DECEMBER 1991}

Kinetic theory of cross-modulation in a weakly ionized plasma. A. J. M. GarRetT

Convection in a plasma with opposed temperature and density gradients. L. Nocera

Resistive tearing-mode instability in a current sheet with equilibrium viscous stagnation-point flow. T. D. PhaN and B. U. Ö. SonneruP

Magnetic fluctuations and kinetic equations in a two-species plasma. A. Di ViTa

Resistive evolution of a force-free plasma to equilibrium. A. S. GILL and E. W. LAING

Amplification of nonlinear surface waves in an inhomogeneous transition layer. G. Brodin and O. M. Gradov 
Low-frequency instability excited by a mesh grid in a double-plasma device. J. Chutia, S. Sato, H. Kubo and Y. Nakamura

Guiding-centre orbits for particles in cross-field devices. S. Riyopoulos

An exact formula for the thermal and particle diffusivities based on the diffusive transport model in tokamak plasmas. C. JANICKI

General dispersion relation for surface waves on a plasma-racuum interface: an image approach. G. W. Rowe

Author Index to Volume 46 


\section{JOURNAL OF PLASMA PHYSICS}

\section{Volume 46 Part 3 December 1991}

\section{CONTENTS}

Kinetic theory of cross-modulation in a weakly ionized plasma A. J. M. GARRETT

Convection in a plasma with opposed temperature and density gradients

LUIGI NOCERA

Resistive tearing-mode instability in a current sheet with equilibrium viscous stagnation-point flow

T. D. PHAN AND B. U. Ö. SONNERUP

Magnetic fluctuations and kinetic equations in a two-species plasma

ANDREA DI VITA

Resistive evolution of a force-free plasma to equilibrium A. S. GILL AND E. W. LAING

Amplification of nonlinear surface waves in an inhomogeneous transition layer

G. BRODIN AND O. M. GRADOV

Low-frequency instability excited by a mesh grid in a doubleplasma device

J. CHUTIA, S. SATO, H. KUBO AND Y. NAKAMURA

Guiding-centre orbits for particles in cross-field devices SPILIOS RIYOPOULOS

An exact formula for the thermal and particle diffusivities based on the diffusive transport model in tokamak plasmas CHRISTIAN JANICKI

General dispersion relation for surface waves on a plasma-vacuum interface: an image approach G. W. ROW E 